the cut off point, this difference was significant at a $p$ value of $<0.025$ by $\chi^{2}$. Comparison of days 0 to 9 and 10 to 19 showed $47 v 67$ days of otitis media, $85 v 72$ days of diarrhoea, and $52 v$ 58 days with cough; no convulsions occurred.

\section{Discussion}

The tendency in the past to attribute serious disease to teething was so prevalent that in 1842 teething was the registered cause of death in $4.8 \%$ of all infants who died in London under the age of 1 year and $7 \cdot 3 \%$ of those between the ages of 1 to 3 years according to the Registrar General's report. ${ }^{2}$ Although today no such connection is worthy of consideration, the question remains as to whether minor symptoms, especially fever, are associated with teething.

Most texts express opinions without any factual basis. 'There is no definite evidence to support claims of accompanying temporary systemic disturbance. Such disturbance, the most common of which are low grade fever, facial rash and mild diarrhoea are not attributable to eruption of teeth'. 'In the olden days it was a custom to blame teeth for colds, diarrhoea and fever'. ${ }^{5}$ An earlier paediatric text in 1907 noted 'there may be a slight fever and restless- ness with loss of appetite associated with the eruption of a tooth'.

From the data presented here it would seem that the 'granny's tale' that infants cut their teeth with fever is supported. We would like to stress the danger in attributing fever to teething without ruling out other pathology. Children are teething from about 6 months to 6 years and therefore can easily be found to be teething when ill from other causes. Only the eruption of the first tooth is a clear landmark and so this study limited itself to the period before its emergence. We are intrigued by our finding and have no explanation to offer at this stage for the observation.

We were taught as students to listen to parents; grandma seems also to have had something to tell us.

1 Illingworth RS. The normal child. 3rd Ed. London: Churchill 1964:77-80.

2 Guthrie L. Teething. BMf 1908;ii:468.

3 Bennett AJ, Bradno DS. The teething virus. Pediatr Infect Dis 1986;5:399-401.

4 Nelson WE, ed. Textbook of pediatrics. 9th Ed. Philadelphia: WB Saunders, 1969:756.

5 Spock B. Baby and child care. New York: Pocket Books, 1968:243.

Kerley CG. The treatment of the diseases of children. Philadelphia: WB Saunders, 1907:36.

\title{
Growth patterns after surgery for virilising adrenocortical adenoma
}

\section{Hospital for Sick} Children, Great Ormond Street, London WC1N 3JH A T Salt D B Grant

Department of Paediatric Endocrinology, St Bartholomew's Hospital, London M O Savage

Correspondence to: Dr Grant.

Accepted 7 October 1991

(Arch Dis Child 1992;67:234-6)

A T Salt, M O Savage, D B Grant

\begin{abstract}
Analysis of growth in nine girls after successful surgical removal of a virilising adrenocortical adenoma showed that five girls continued to grow rapidly for up to 18 months after operation and subsequently had normal growth velocities. The other four girls grew at normal rates after surgery. Only one girl showed progressive advance in bone age after operation and she subsequently had precocious puberty.
\end{abstract}

Although more than 200 cases of adrenocortical tumour have been described in the literature, ${ }^{12}$ the natural history of growth and pubertal development after successful surgery has been poorly documented. This paper describes the growth patterns after surgery in nine girls who presented between 1969 and 1988 with virilisation due to adrenocortical adenomas.

\section{Patients and methods}

The hospital records of nine girls born between 1965 and 1986 who had successful surgical resection of an adrenocortical adenoma were reviewed. Clinical details of these patients are given in the table. All the subjects were 4 years old or less at the time of diagnosis and five had symptoms for less than three months before presentation. Virilisation with clitoromegaly and growth of pubic hair was present in all cases but two also showed features of Cushing's syndrome; one of the latter patients (case 1) also had hemihypertrophy and was hypertensive at presentation. In all cases the tumours were well encapsulated and apparently complete resection was possible. Tumour weight ranged from 10 to $40 \mathrm{~g}$ in all but one case in which a larger tumour $(193 \mathrm{~g})$ with some features of a carcinoma was found.

All measurements were obtained using a Harpenden stadiometer and bone age was assessed by two observers using the TannerWhitehouse radius, ulna, and short bones (RUS) method. Only reported heights were available for parents. Duration of follow up after surgery ranged from 2.5 to over 20 years (median 10 years).

\section{Results}

Information on height and bone age at the time 
Initial clinical features and follow up findings in nine girls who had resection of a virilising adrenocortical adenoma in early childhood. Details of reported mid-parental height are also given

\begin{tabular}{|c|c|c|c|c|c|c|c|c|c|}
\hline & \multicolumn{9}{|l|}{ Cases } \\
\hline & 1 & 2 & 3 & 4 & 5 & 6 & 7 & 8 & 9 \\
\hline \multirow{2}{*}{\multicolumn{10}{|c|}{ Features at diagnosis }} \\
\hline Age (years) & $3 \cdot 4$ & $2 \cdot 7$ & $0 \cdot 7$ & & & & & & $2 \cdot 5$ \\
\hline Duration of symptoms (years) & 1.5 & 0.5 & $0 \cdot 1$ & $0 \cdot 2$ & $0 \cdot 8$ & $0 \cdot 3$ & $0 \cdot 2$ & $0 \cdot 3$ & 0.5 \\
\hline Clinical features & $\mathrm{V}+\mathrm{C}$ & & $\mathrm{V}+\mathrm{C}$ & & & & & & V \\
\hline Height $(\mathrm{cm})$ & $100 \cdot 5$ & $89 \cdot 0$ & $72 \cdot 0$ & $104 \cdot 0$ & $94 \cdot 0$ & $98 \cdot 4$ & 93.6 & $81 \cdot 3$ & $93 \cdot 6$ \\
\hline Height SD scores & $+1 \cdot 0$ & -0.5 & +0.8 & $+0 \cdot 7$ & $+1 \cdot 4$ & $+3 \cdot 1$ & $+3 \cdot 3$ & +0.1 & $+1 \cdot 2$ \\
\hline Bone age (years) & 6.4 & $4 \cdot 4$ & 0.7 & - & $3 \cdot 2$ & 5.9 & $4 \cdot 1$ & $2 \cdot 0$ & $3 \cdot 0$ \\
\hline \multicolumn{10}{|l|}{ Findings at last review } \\
\hline Age (years) & $25 \cdot 0$ & $18 \cdot 0$ & $15 \cdot 0$ & $8 \cdot 6$ & $12 \cdot 0$ & $11 \cdot 0$ & $9 \cdot 0$ & $3 \cdot 5$ & $4 \cdot 7$ \\
\hline Height $(\mathrm{cm})$ & $178 \cdot 0$ & $165 \cdot 0$ & $166 \cdot 7$ & $132 \cdot 5$ & $171 \cdot 0$ & $162 \cdot 2$ & $142 \cdot 0$ & $99 \cdot 5$ & $111 \cdot 0$ \\
\hline Height SD score & $+2 \cdot 6$ & +0.5 & +0.8 & $+0 \cdot 7$ & +3.6 & $+2 \cdot 8$ & $+2 \cdot 0$ & +0.7 & $+1 \cdot 3$ \\
\hline Menarche & $12 \cdot 0$ & $14 \cdot 0$ & $12 \cdot 4$ & $\mathbf{P}$ & & $\mathbf{P}$ & & $\mathbf{P}$ & $\mathbf{P}$ \\
\hline \multicolumn{10}{|l|}{ Last hand radiograph } \\
\hline Age (years) & $7 \cdot 9$ & $3 \cdot 7$ & - & - & $10 \cdot 4$ & - & $8 \cdot 1$ & 3.5 & - \\
\hline Bone age (years) & $8 \cdot 0$ & $4 \cdot 3$ & - & - & 10.5 & - & $10 \cdot 7$ & $4 \cdot 0$ & - \\
\hline Mid-parental height SD score & NK & +0.9 & $+1 \cdot 1$ & $+1 \cdot 0$ & $+1 \cdot 7$ & $+1 \cdot 5$ & $-1 \cdot 5$ & +0.5 & $+1 \cdot 1$ \\
\hline
\end{tabular}

NK, not known (adopted); V, virilisation with clitoromegaly; C, cushingoid; P, premenarcheal.

of diagnosis and height when last reviewed is given in the table. Standard deviation (SD) scores for height are also given, as are the initial bone age findings.

\section{HEIGHT AND BONE AGE AT PRESENTATION}

At presentation, the height of all but one girl (case 2) was above the 50th centile and in two girls height was over 3 SD scores above the mean for age. These two cases, who had symptoms of virilisation for three and six months before diagnosis, were inappropriately tall when compared with reported mid-parental height. In five of the other girls who were taller than average, height was in keeping with midparental height. Thus, despite evidence of androgen production for up to 18 months before diagnosis, only two girls were inappropriately tall at presentation. Bone age was advanced by more than one year in four girls at the time of diagnosis and in two of these subjects height was more than 3 SD scores above average.

\section{POSTOPERATIVE GROWTH AND PUBERTAL}

DEVELOPMENT

Two different patterns of growth and adolescent development were observed in the nine girls after surgery. In five (cases $1,3,5,6,8$ ), rapid growth continued for up to 18 months after operation and subsequent growth velocity was normal, height remaining above the 97 th centile in two girls (cases 5 and 6). In the remaining girls growth was at a normal rate after operation with no evidence of deceleration after removal of the tumour.

Adult height is only available in two subjects, who were aged 18 and 25 when last reviewed (cases 1 and 2). Although both girls had significant advanced bone ages when first seen, adult height SD scores were greater than the height SD scores at diagnosis. Four further girls have reached the ages of 9 to 15 years but only one (case 7) has gone on to show evidence of precocious puberty. The girl's bone age was advanced by $2 \cdot 4$ years at diagnosis, and although her postoperative growth rate was normal, bone age continued to advance; at $7 \cdot 5$ years she had stage 2 breast development. She has been treated with cyproterone acetate and has not yet undergone menarche. Five other girls were premenarcheal when last seen, but it is not possible to comment on the pubertal pattern in two of them who were still less than 5 years old.

\section{Discussion}

These nine girls showed the typical clinical features of a virilising adrenocortical tumour with clitoromegaly and early growth of pubic hair. ${ }^{3}$ While their tall stature at diagnosis suggested androgen induced acceleration of growth, in seven cases reported mid-parental height was above average and in only two was height greater than that expected from midparental height.

In most of the early reports on children with adrenocortical adenomas it has been assumed that adult height would be compromised because of advanced bone age at the time of diagnosis. ${ }^{45}$ However, the above findings do not support this view and it appears that in many girls the prognosis for adult height after the removal of an adrenocortical adenoma may be good, despite the presence of advanced bone age at presentation. While in four of our patients bone age was advanced by more than one year, in all but one case there was a trend for bone age to come back in line with chronological age after surgery. There was no 'catch-down' of growth after surgery and all the subjects grew along or above the centile line achieved at presentation. Thus all the girls have remained tall for the duration of follow up and the two subjects who have reached adult height are taller than might have been expected from their height SD scores at the time of diagnosis.

Precocious puberty after successful removal of a virilising adrenocortical adenoma was reported by Lee et al who described two children, both aged 4 years at the time of surgery, with considerably advanced bone ages (9 and 11 years) who developed precocious puberty. ${ }^{4}$ In one this occurred at 8.5 years and in the other isosexual pubertal development continued after surgery although virilisation regressed. However, only one of our patients showed a similar pattern of development, with 
progressive advance in bone age associated with precocious puberty.

In conclusion, the above results indicate that the prognosis for adult height in girls who have had successful surgery for a virilising adrenal tumour may be good despite significant advance in bone maturation at diagnosis. In some patients acceleration of growth continues for some time after surgery but continued advance of bone maturation associated with precocious puberty may be relatively uncommon.
1 Hayles AB, Hahn HB, Sprague RG, Bahn RC, Priestley JT. Hormone secreting tumors of the adrenal cortex in Hormone secreting tumors of the
children. Pediatrics 1966;37:19-25.

2 Forest MG. Adrenal steroid excess: virilizing adrenal tumours. In: Brook CGD, ed. Paediatric endocrinology London: Blackwell, 1989:424-7.

3 Kenny FM, Hashida Y, Askari HA, Sieber WH, Fetterman $\mathrm{GH}$. Virilizing tumors of the adrenal cortex. Am $\mathcal{F}$ Dis Child 1986;115:445-8.

4 Lee PDK, Winter RJ, Green OC. Virilizing adrenocortical tumors in childhood: eight cases and review of the literature. Pediatrics 1985;76:437-44.

5 Burrington JD, Stephens CA. Virilizing tumours of the adrenal gland in childhood: report of eight cases. $\mathcal{F}$ Pediatr Surg 1969;4:291-302. 